\title{
New warning label for opioid products
}

Aust Prescr 2020;43:172

https://doi.org/10.18773/ austprescr.2020.059

First published

11 August 2020
In 2018 the Therapeutic Goods Administration (TGA) released a consultation paper called Prescription strong (Schedule 8) opioid use and misuse in Australia - options for a regulatory response. One of the regulatory options was the addition of a warning on the packaging of opioid products identifying the risks of overdose and dependence. ${ }^{1,2}$

In collaboration with other organisations, the Pharmaceutical Society of Australia (PSA) has now developed a cautionary advisory label warning of the risk of opioid overdose and dependence. These labels are applied by pharmacists to medicines at the time of dispensing and are intended to be used as an aid to counselling patients about the safe and effective use of medicines. The label for opioids is:

se of this medicine has the risks of overdose and dependenco
As an additional counselling aid for patients, families and carers, a patient information handout has been developed. It is available in the Australian Pharmaceutical Formulary. Pharmacists may provide patients with this handout at the time of dispensing.

\section{REFERENCES}

1. Therapeutic Goods Administration. Consultation: Prescription strong (Schedule 8) opioid use and misuse in Australia - options for a regulatory response. Canberra: Australian Government Department of Health; 2018 May 23. https://www.tga.gov.au/consultation/consultationprescription-strong-schedule-8-opioid-use-and-misuseaustralia-options-regulatory-response [cited 2020 Aug 3]

2. Therapeutic Goods Administration. Submissions received and next steps: Prescription strong (Schedule 8) opioid use and misuse in Australia - options for a regulatory response. Canberra: Australian Government Department of Health; 2018 Sep 12. https://www.tga.gov.au/submissions-receivedand-next-steps-prescription-strong-schedule-8-opioid-useand-misuse-australia-options-regulatory-response [cited 2020 Aug 3] 